\title{
The hydrogen embrittlement sensitivity of duplex stainless steel with different phase fractions evaluated by in-situ mechanical testing
}

\author{
Margo Cauwels, Lisa Claeys, Tom Depover, Kim Verbeken \\ Ghent University, Department of Materials, Textiles and Chemical Engineering, Technologiepark. 46, 9052 Zwijnaarde, Belgium \\ Margo.Caunels@UGent.be \\ Lisa.Claeys@UGent.be \\ Tom.Depover@UGent.be, bttp://orcid.org/0000-0002-8856-1122 \\ Kim.Verbeken@UGent.be,http://orcid.org/0000-0002-5190-016X
}

\begin{abstract}
The influence of the austenite $(\gamma)$ phase fraction on the hydrogen embrittlement of duplex stainless steel is investigated. Heat treatments are performed to create two duplex stainless steel specimens, containing $50 \%$ and $44 \%$ of austenite, respectively. Mechanical testing with and without hydrogen charging reveals that significant embrittlement occurs regardless of the austenite fraction. A higher austenite fraction results in a reduced ductility loss under the presence of hydrogen. Samples with a higher ferrite fraction are embrittled more due to their higher hydrogen diffusivity. In-situ tensile tests, interrupted at the ultimate tensile strength, show hydrogen-assisted cracks on the specimen surface both in austenite and ferrite and across the $\alpha / \gamma$ interface.
\end{abstract}

KEYwORDS. Hydrogen embrittlement; Duplex stainless steel; In-situ mechanical testing

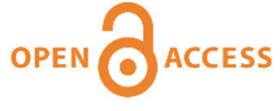

Citation: Cauwels, M., Claeys, L., Depover, T., Verbeken, K., The hydrogen embrittlement sensitivity of duplex stainless steel with different phase fractions evaluated by in-situ mechanical testing, Frattura ed Integrità Strutturale, 51 (2020) 449-458.

Received: 31.10 .2019

Accepted: 03.12.2019

Published: 01.01.2020

Copyright: (C) 2019 This is an open access article under the terms of the CC-BY 4.0, which permits unrestricted use, distribution, and reproduction in any medium, provided the original author and source are credited.

\section{INTRODUCTION}

$\mathrm{D}$ uplex stainless steels (DSS) are a family of stainless steel grades characterised by a mixed microstructure of austenite $(\gamma$, FCC crystal structure) and ferrite ( $\alpha$, BCC crystal structure). They combine high mechanical strength with excellent corrosion resistance. DSS are therefore attractive materials for application in a diverse range of industries, such as energy, marine, petrochemical, paper and oil \& gas industry. Their use has largely increased during the last decade.

However, DSS have an important drawback: they are vulnerable to hydrogen embrittlement (HE) and hydrogen induced stress cracking (HISC) [1, 2]. Hydrogen embrittlement is used to refer to a degradation of mechanical properties due to the presence of hydrogen. This phenomenon is mostly reported as a decrease in material ductility and toughness, which can lead to unexpected and premature failure. Hydrogen can enter the DSS during production and processing, for example during welding, or during in-service conditions, such as for cathodically over-protected offshore structures or because of general corrosion that can be aggravated in environments where $\mathrm{H}_{2} \mathrm{~S}$ is present [3-5]. 
Several possible theories for hydrogen embrittlement have been proposed, with the operational mechanism depending on the material, the hydrogen charging condition and the load type [6,7]. No single mechanism can comprehensively describe the HE phenomena and different combinations of mechanisms have also been described [8]. For non-hydride forming materials, hydrogen enhanced decohesion (HEDE), hydrogen enhanced localised plasticity (HELP) and hydrogen enhanced strain-induced vacancies (HESIV) are most commonly cited. HEDE is the oldest proposed mechanism and proposes hydrogen induced weakening of interatomic bonds, as such promoting decohesion in the lattice [9-11]. The HELP model is based on atomic hydrogen enhancing dislocation mobility through an elastic shielding effect. This locally reduces the shear strength, leading to premature fracture [12-14]. Finally, according to the HESIV theory, hydrogen stabilises vacancies and reduces their mobility, increasing the strain-induced creation of vacancies and reducing the material ductility $[15,16]$. Hydrogen induced ductility loss of DSS under cathodic protection in artificial seawater or $\mathrm{NaCl}$-containing solutions has been reported in several studies [4,17-21]. The hydrogen susceptibility was found to be more pronounced for welded DSS because of microstructural changes and a higher ferrite content in the heat affected zone as compared to the base metal [22]. The hydrogen properties of the two phases in DSS are very different. In ferrite, the hydrogen diffusion is relatively high but the hydrogen solubility is low, while for austenite the reverse is true [23]. Usually, $\alpha$ and $\gamma$ are present in equal fractions in commercial DSS to obtain an optimal combination of mechanical properties. An austenite phase fraction that differs from this ideal $50 \%$ is relevant for example in the heat affected zone of welded DSS structures. This work aims to study the influence of the austenite phase fraction on the hydrogen embrittlement sensitivity of DSS. First, two heat treatments were devised in order to create DSS samples with a different austenite phase fraction. Thereafter, tensile tests were performed both with and without the presence of hydrogen. The tests without hydrogen were performed in air and tests with hydrogen were performed in-situ, i.e. with continuous electrochemical hydrogen charging during the tensile test, using pre-charged specimens.

\section{MATERIALS AND EXPERIMENTAL PROCEDURE}

$\mathrm{T}$ he material used was UNS S32205 duplex stainless steel, hot rolled to plates of $0.8 \mathrm{~mm}$ thickness. The chemical composition is given in Tab. 1. The as-received material contained $53 \%$ ferrite as determined via magnetic measurements (Feritscope ${ }^{\circledR}$ FMP30). The steel was subjected to two different heat treatments in order to create materials with a differing austenite fraction: one with equal fractions of ferrite and austenite, and another with approximately $40 \%$ austenite. The samples were heated to a temperature were the desired phase balance was present, followed by quenching in a brine solution $(7 \mathrm{wt} \% \mathrm{NaCl})$. The required annealing temperatures were chosen based on Thermocalc ${ }^{\circledR}$ calculations as $1190 \quad{ }^{\circ} \mathrm{C}$ and $1110{ }^{\circ} \mathrm{C}$ for the $40 \% \gamma$ and $50 \% \gamma$ samples, respectively. Annealing times were selected to ensure similar grain sizes in both heat treated materials, since grain size influences both the hydrogen behaviour of a material, as well as its mechanical properties. $10 \mathrm{~min}$ was selected for the samples annealed at $1190{ }^{\circ} \mathrm{C}$ and $30 \mathrm{~min}$ was chosen for the samples annealed at $1110^{\circ} \mathrm{C}$. The resulting two heat treated materials will be referred to as HT 1190 and HT 1110 in the following sections.

\begin{tabular}{|c|c|c|c|c|c|c|c|}
\hline $\mathrm{wt} \%$ & C & $\mathrm{Cr}$ & $\mathrm{Ni}$ & Mo & $\mathrm{Mn}$ & $\mathrm{Si}$ & Other \\
\hline UNS S32205 & 0.022 & 22.850 & 5.500 & 3.070 & 1.810 & 0.320 & $\mathrm{Cu} 0.200, \mathrm{P} 0.027$, Co 0.162, N 0.173, Al 0.022 \\
\hline
\end{tabular}

Table 1: Chemical composition of UNS S32205

The heat treated materials were etched with Carpenter stainless steel etchant (8.5 g Ferric Chloride, $2.4 \mathrm{~g}$ Cupric Chloride, $122 \mathrm{ml}$ ethanol, $122 \mathrm{ml}$ hydrochloric acid and $6 \mathrm{ml}$ nitric acid) and investigated using light optical microscopy (Keyence VHX-2000), scanning electron microscopy (Quanta FEG 450, accelerating voltage $20 \mathrm{kV}$, spot size $5 \mathrm{~nm}$ ) in combination with energy-dispersive X-ray analysis (EDX), and electron backscatter diffraction (EBSD). Phase fractions were determined using a Feritscope ${ }^{\circledR}$ FMP30.

Tensile tests were performed on non-notched samples. The sample geometry is given in Fig. 1. Samples were heat treated in a resistance furnace $\left(\mathrm{Nabertherm}^{\circledR}\right)$ and subsequently ground and polished to remove oxides. Both materials were tested in uncharged condition in air, as well as in hydrogen charged condition, to evaluate the impact of hydrogen on the mechanical properties. The hydrogen charged condition consisted of pre-charging for one day followed by in-situ charging during the tensile test. Hydrogen charging was done electrochemically in a $0.5 \mathrm{M} \mathrm{H}_{2} \mathrm{SO}_{4}$ solution containing $1 \mathrm{~g} / 1$ thiourea with an applied constant current density of $0.8 \mathrm{~mA} / \mathrm{cm}^{2}$. Continuous in-situ hydrogen charging ensured that hydrogen did not 
diffuse out of the sample during testing. The tests were performed at a constant cross-head displacement speed of $0.6 \mathrm{~mm} / \mathrm{min}$, which corresponded to a strain rate of $1 \cdot 10^{-3} \mathrm{~s}^{-1}$. Fracture surfaces were investigated using SEM. Tensile tests were also interrupted before fracture (stopped at an elongation where the ultimate tensile strength (UTS) was just reached) to study hydrogen-assisted cracking on the sample surfaces.

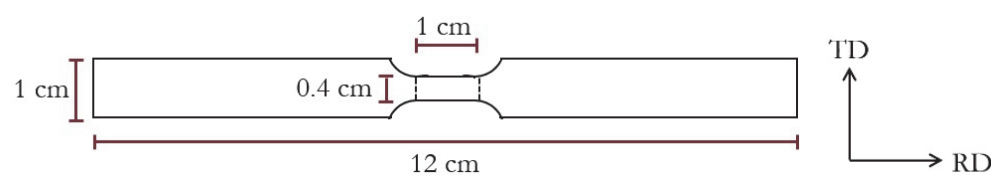

Figure 1: Geometry of tensile samples

\section{RESULTS AND DISCUSSION}

\section{Material characterization}

$\mathrm{O}$ ptical microscopy (Fig. 2) revealed a strongly oriented microstructure as a result of hot rolling. On the longitudinal section (TD plane) elongated austenite 'rods' (light coloured phase on Fig. 2) were observed parallel with the rolling direction, embedded in a ferrite 'matrix' (darker coloured phase on Fig. 2). The samples were free of intermetallic sigma phase, which may precipitate during heat treatment of DSS [24]. The average grain diameter on the TD plane was determined using the linear intercept method until a relative accuracy $(\% \mathrm{RA})$ lower than $10 \%$ at a confidence level of $95 \%$ was reached. This resulted in $5.18 \pm 0.51 \mu \mathrm{m}$ for HT 1190 and $4.42 \pm 0.34 \mu \mathrm{m}$ for HT 1110. The phase balance in both heat treated samples, determined by EBSD and Feritscope ${ }^{\circledR}$ measurements, is given in Tab. 2. Magnetic measurements $\left(\right.$ Feritscope $^{\circledR}$ ) were considered to be more reliable since they analyze a relatively large volume of material compared to EBSD, which is a local 2D technique and might therefore not be representative for the entire sample. The HT 1110 sample had an austenite phase fraction close to the intended 50\%, while the HT 1190 sample had an austenite content close to $44 \%$.

\begin{tabular}{ccc}
\hline$\gamma \%$ & HT 1190 & HT 1110 \\
EBSD & $39.20 \pm 2.40$ & $46.10 \pm 1.09$ \\
Feritscope ${ }^{\circledR}$ & $43.91 \pm 1.15$ & $49.83 \pm 0.95$ \\
\hline
\end{tabular}

Table 2: Average austenite fraction $\gamma \%$ for the different heat treatments, as determined by EBSD and Feritscope ${ }^{\circledR}$.
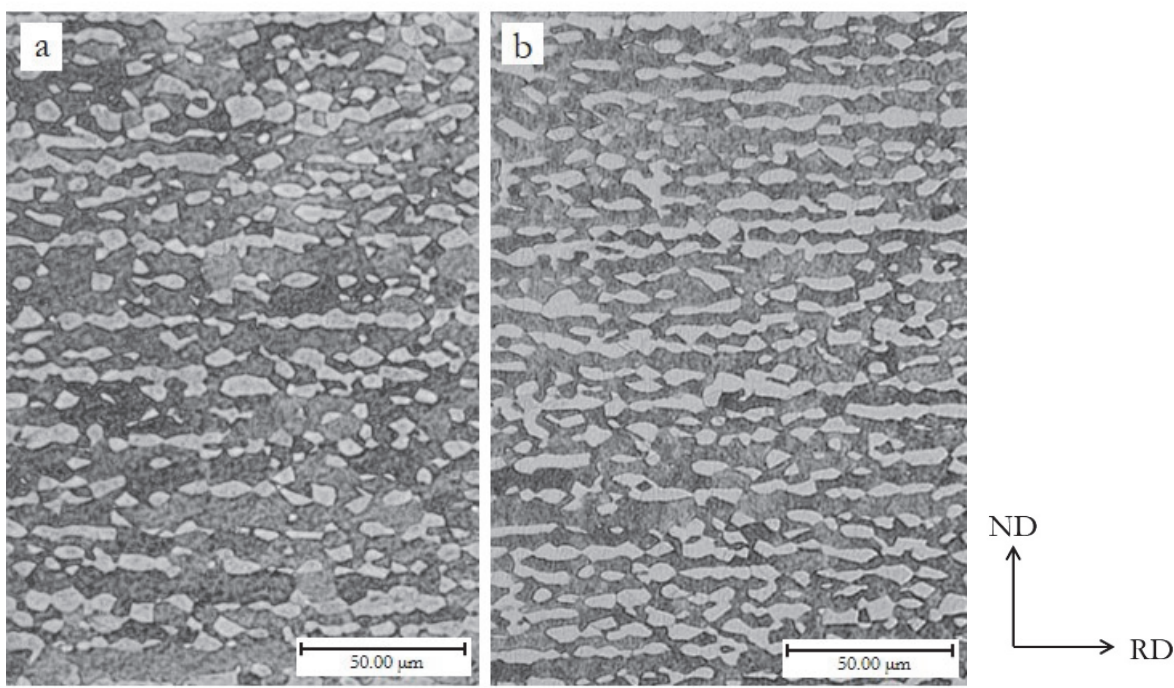

Figure 2: Optical microscopy images of the TD plane of (a) HT 1190 and (b) HT 1110. 


\section{Hydrogen induced mechanical degradation}

Fig. 3 shows the engineering stress-strain curves for the samples tested in air (full lines) and for those tested in hydrogen charged condition (dotted lines). Although some experimental variation can be detected on the mechanical data, trends are still reproducible and valid for further evaluation. A possible explanation for the experimental spread is the microstructural nature of heat treated DSS material, while the tested samples were only between 0.600 and $0.700 \mathrm{~mm}$ thick, increasing the possibility of having different amounts of austenite at the edges where hydrogen is entering the material. Additionally, because of the quenching procedure after the heat treatment, the tensile specimens were geometrically distorted, influencing the reproducibility of the results. Nevertheless, the averaged results are still reliable with clear differences between both material conditions.

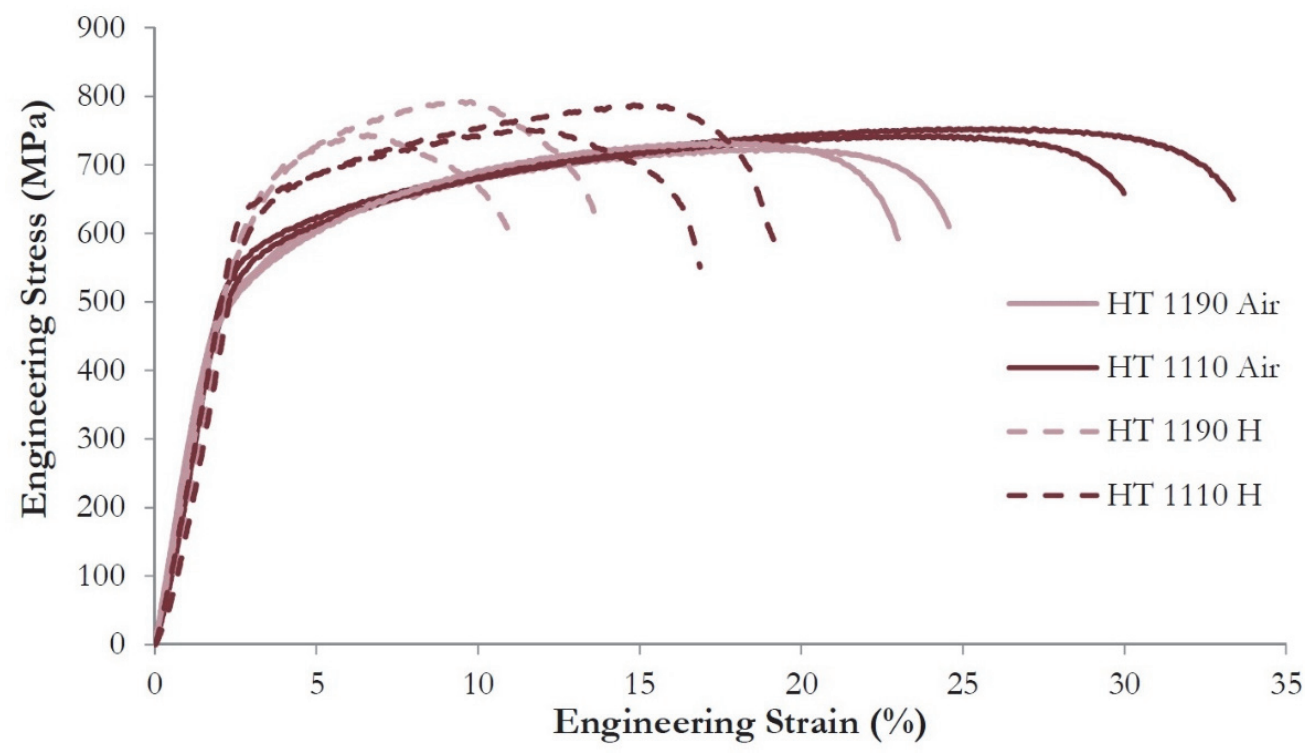

Figure 3: Stress-strain curves of samples tested in air (full lines) and with in-situ hydrogen charging after 1 day of hydrogen pre-charging (dotted line) for both heat treated materials (HT 1190 and HT 1110)

For the tensile tests performed in air, the elongation at fracture increased with an increased austenite phase fraction. This is to be expected since austenite is more ductile compared to ferrite. The ultimate tensile strength of both heat treated materials was similar.

Hydrogen charging has a clear effect on the tensile behaviour of the material. For both heat treatments, there is an evident loss of ductility, seen in the reduction of the total elongation at fracture. Based on the elongation at fracture in air and in hydrogen charged condition, an embrittlement index (EI) was calculated according to the following formula [25]:

$$
\mathrm{EI}=\frac{\text { elongation in air }- \text { elongation when charged }}{\text { elongation in air }}
$$

This resulted in a value of 43.3\% for HT 1190 and 36.5\% for HT 1110. This is in agreement with other findings in literature since ferrite is considered more susceptible to hydrogen embrittlement than austenite [18,26-28]. Moreover, Örnek et al. [29] found that DSS microstructures with a large austenite spacing were more sensitive to HE. The spacing of the austenite ribbons was larger in the HT 1990 sample, both on account of it having a lower austenite fraction and a slightly larger grain size, as mentioned in the previous section and as seen in Fig. 2. HT 1190 also had a higher hydrogen content than HT 1110 after one day of hydrogen charging and Zakrocymski et al. [26] found that the severity of HE in DSS increased with higher hydrogen concentrations. Additionally, the diffusion of hydrogen was faster in HT 1190 samples which contributed to its higher sensitivity to hydrogen [30]. The decrease in ductility is significant, even though the sample was not saturated with hydrogen after one day of hydrogen pre-charging and thus hydrogen is not present throughout the entire thickness of the specimen. Additionally, the yield stress of the material increased in hydrogen charged condition. This effect was more pronounced for HT 1190. The increase of the yield strength after hydrogen charging was also observed in other works, such as in $[26,31]$ for DSS, and in $[32,33]$ for austenitic stainless steels. The strengthening effect of hydrogen can be attributed 
to a combination of effects. First, the pinning of dislocations by hydrogen, impeding cross-slip and dislocation movement, leading to solid solution strengthening [34]. Secondly, Barnoush et al. [35] found that when the hydrogen concentration is high enough, the shear modulus of the austenite is reduced locally. Dislocation sources such as Frank-Read sources, that were previously inactive will then generate new dislocations under the high internal stresses inherently present in the DSS due to the differing thermal expansion coefficients of ferrite and austenite. The generation of new dislocations increases the dislocation density, which in turn increases the stress required to move dislocations, and thus increases the yield strength. Both effects may be increased in the HT 1190 samples compared to the HT 1110 samples due to the higher hydrogen content in those samples.

\section{Evaluation of the fractography and hydrogen-assisted cracks by SEM}

The fracture surface of both materials tested in air showed dimples. A lot of necking occurred for both samples, resulting in a very thin fracture surface due to the large reduction in area. Fig. 4a shows the fracture surface delineated by white lines. The fractured specimens also had a cup-and-cone-like appearance. This, as well as the presence of dimples on the fracture surface indicates a ductile fracture behaviour in air.
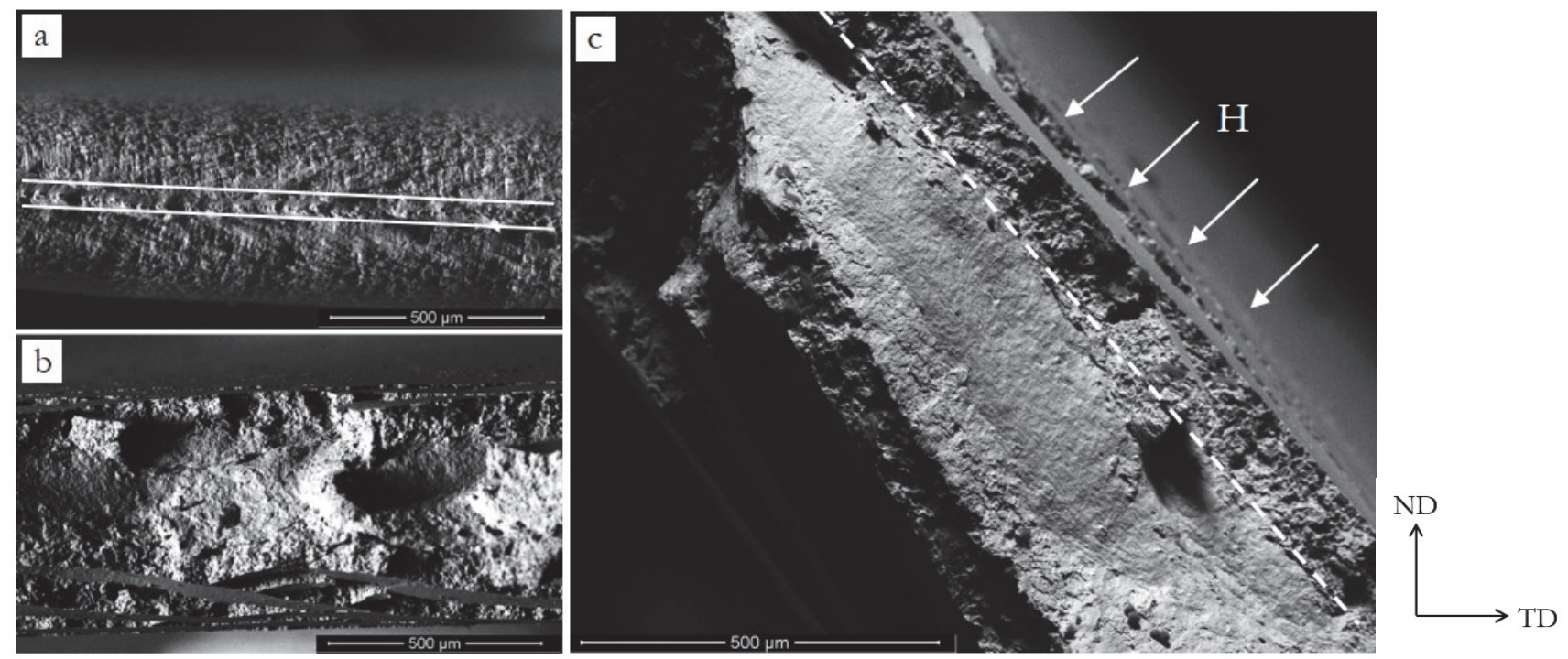

Figure 4: Fracture surface for a HT 1190 sample tested (a) in air, (b) and (c) in hydrogen charged condition. (c) shows the depth of the brittle zone (white dotted line) and the direction of hydrogen entry (white arrows).
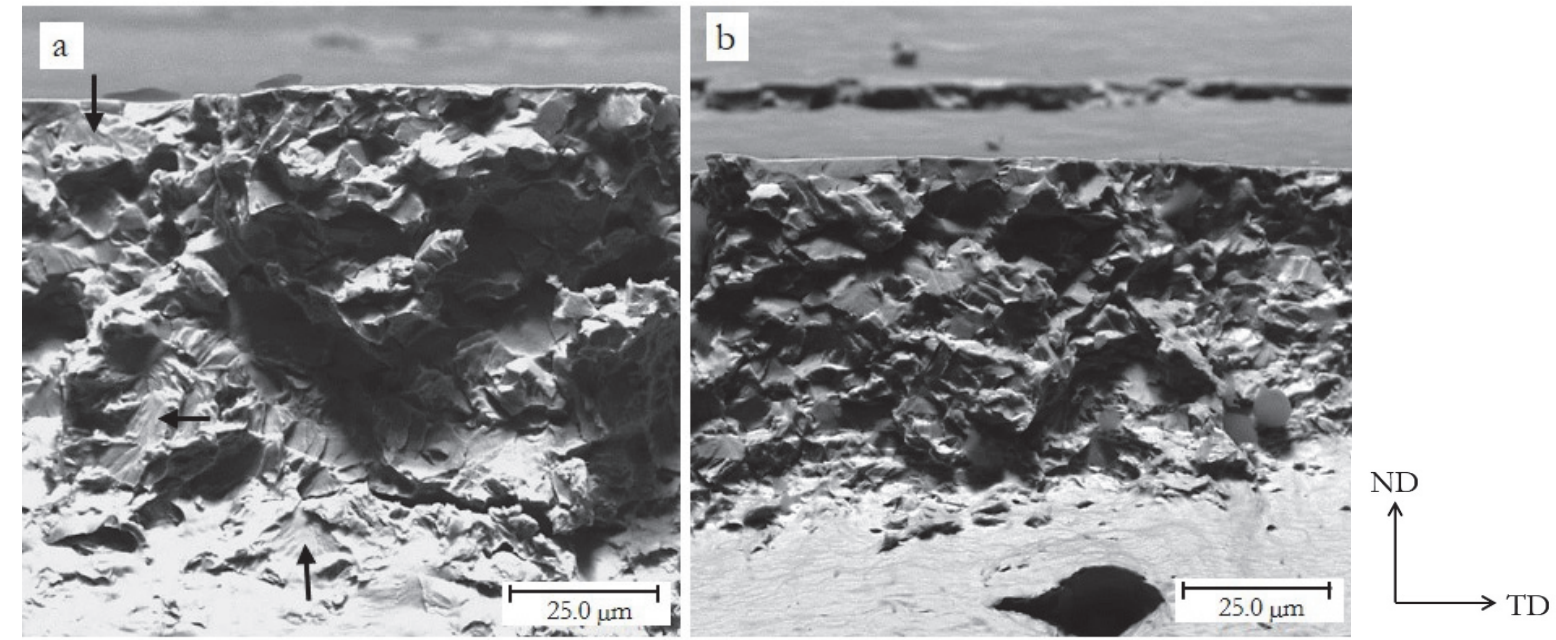

Figure 5: SEM images of the embrittled zone in sample (a) HT 1190 and (b) HT 1110. Arrows indicate examples of river markings. 
In the presence of hydrogen (Fig. 4b), the appearance of the fracture surface is clearly different. Near the edges of the sample, brittle fracture features were observed. In the centre, still ductile fracture features such as dimples were observed. In between, a transition shear zone was observed. On Fig. 4c, the dashed line indicates the size of the brittle zone. This distinct fracture surface is a consequence of hydrogen not being present throughout the entire thickness of the sample after one day of pre-charging, considering the relatively slow diffusion of hydrogen in DSS. The side (ND) surfaces of the hydrogen charged samples showed secondary cracks which were not present when specimens were tested in uncharged condition.

Fig. 5 shows the embrittled zone in detail for both heat treatments. These images show a combination of (quasi-)cleavage and intergranular fracture features. Quasi-cleavage is used to refer to features on a fracture surface that exhibits characteristics of both plastic deformation and cleavage. For quasi-cleavage, the fracture surface has the appearance of a cleavage fracture, but is not along a known cleavage plane $[36,37]$. This is an often observed feature for fracture of ferrous alloys which are susceptible to HE [38]. Quasi cleavage is often characterised by fine lines that follow the crack propagation direction called 'river markings' (Fig. 5a). A smaller part of the brittle features for both heat treated samples was intergranular. There was some indication that intergranular fracture was more common for the HT 1110 sample than the HT 1190 sample. After one day of hydrogen pre-charging, the samples are not saturated with hydrogen. The depth of the area affected by hydrogen was measured on several SEM images and averaged out resulting in a depth of embrittlement of $66.78 \pm 1.8 \mu \mathrm{m}$ for HT 1190 and $56.43 \pm 0.8 \mu \mathrm{m}$ for HT 1110. The hydrogen concentration $C_{H}$ throughout the sample can be modelled by solving Fick's second law for uniaxial diffusion in a thin plate [23]. A qualitative representation of the hydrogen profiles in HT 1190 and HT 1110 tensile samples with a thickness of $0.650 \mathrm{~mm}$ after one day of hydrogen charging is given in Fig. 6 . As HT 1190 has a higher ferrite fraction, hydrogen can diffuse further into the material due to a higher average diffusion coefficient [39]. The average diffusion coefficient of hydrogen in DSS depends on austenite fraction, as well as the shape, size and spacing of the austenite and its orientation in relation to the direction of hydrogen entry into the material. The lower austenite fraction and larger grain size of the HT 1190 sample contribute to a less tortuous path for hydrogen diffusion and less opportunity for hydrogen to get trapped at the $\alpha / \gamma$ interface. The diffusion coefficients used for this calculation were $1.14 \cdot 10^{-14} \mathrm{~m}^{2} \cdot \mathrm{s}^{-1}$ for HT 1190 and $3.37 \cdot 10^{-15} \mathrm{~m}^{2} \cdot \mathrm{s}^{-1}$ for HT 1110 These coefficients were determined by fitting Fick's diffusion law to a saturation curve for each respective material following the procedure established by Claeys et al. in [40]. Also based on Fick's diffusion law, the distance $\mathrm{x}$ hydrogen can theoretically diffuse into the material in a given time $\mathrm{t}$ is given by the formula:

$$
\mathrm{x}=\sqrt{\mathrm{Dt}}
$$

Fick's laws for diffusion, however, assume a homogeneous microstructure, which is certainly not the case for DSS. Application of Eqn. (2) using the experimentally determined diffusion coefficients mentioned above, results in 31.4 $\mu \mathrm{m}$ and $17.07 \mu \mathrm{m}$ for HT 1190 and HT 1110, respectively. This is a considerable underestimation of the diffusion depth compared to the values measured on SEM images. In DSS, hydrogen will not be distributed uniformly over austenite and ferrite. Since the diffusion coefficient of hydrogen in ferrite is much larger than the one in austenite, hydrogen will diffuse deeper into the material following ferrite 'paths', where diffusion is faster than the overall, effective diffusion speed, while diffusion in austenite contributes little to the overall hydrogen transport [39]
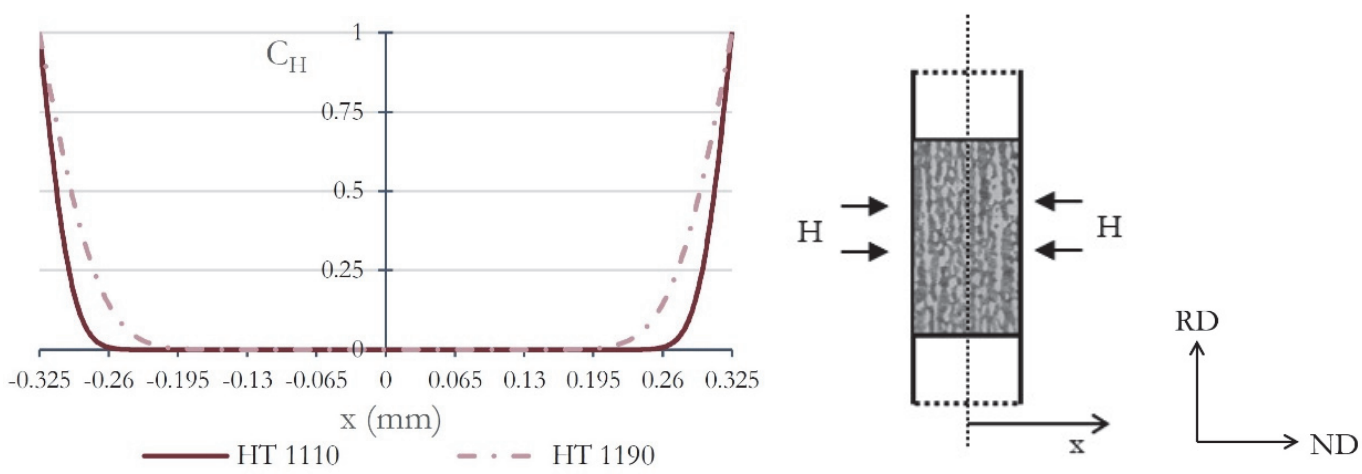

Figure 6: Simulated normalised hydrogen concentration profile through the thickness of a tensile sample after one day of hydrogen charging for HT 1190 and HT 1110 
Secondary cracks on the ND surface were further examined on tensile samples that were stopped at an intermediate elongation at which ultimate tensile strength was just reached. These cracks were primarily transgranular. Crack growth is reported to occur preferentially in ferrite $[17,18]$ and Zheng and Hardie [41] report that austenite acts as an obstacle to crack propagation since it is both more ductile and less susceptible to HE. For both HT 1190 and HT 1110, cracks across the austenite-ferrite interface were often present (Fig. 7a) as well as cracks that were seemingly unconnected to any ferrite grains (Fig. 7b). Oltra et al. [42] proposed a mechanism for hydrogen cracks in the austenitic phase of a DSS that cross a phase boundary. Cracking starts with brittle cleavage in ferrite, which induces a micro-crack in the adjacent austenite grain when it reaches the $\alpha / \gamma$ boundary. This allows a supply of hydrogen from the ferrite to the austenite at the crack tip, and particularly along slip planes. Local hydrogen accumulation increases dislocation mobility, as per the HELP mechanism, leading to pile-ups ahead of the enhanced plasticity zone [43]. At a critical stress, a new crack is formed at the pile-up and the hydrogen crack can begin to propagate from the initial micro-crack. The sequence can then start again at the new crack, and this process can be expected to lead to regular changes in crack plane. The crack in Fig. 7c, and some of the cracks in Fig. $7 \mathrm{~b}$ are examples of cracks that most likely propagated via this proposed mechanism. Claeys [44] also noted that when charging in $\mathrm{H}_{2} \mathrm{SO}_{4}$, probably there is sufficient hydrogen accumulation in austenite to initiate cracks as an alternative starting point for this mechanism in DSS, and cleavage in ferrite is not strictly necessary.

'Zigzag' cracks were also observed in austenite. An example of such a crack in an austenite grain in HT 1190 is indicated on Fig. 8a with a white arrow. The shape of this crack can be a consequence of the micro-cracks alternating different slip planes while it propagates [42]. Alternatively, Koyama et al. [45] described hydrogen-assisted cracks in an austenitic steel occurring along primary and secondary twins also resulting in a zigzag pattern. Finally, Fig. 8b shows cracking around inclusions. The inclusions were identified as alumina by EDX, which can originate from the desoxidation step in the steel production process, when $\mathrm{Al}$ is added. Laureys et al. [46] found that hydrogen-induced crack initiation was linked to alumina particles in ultra-low carbon steel, and a mechanism for this phenomenon was proposed by Tiegel et al. [47]: as hydrogen accumulates at incoherent particle interfaces leading to interface debonding and vacancy stabilisation, leading to crack initiation.
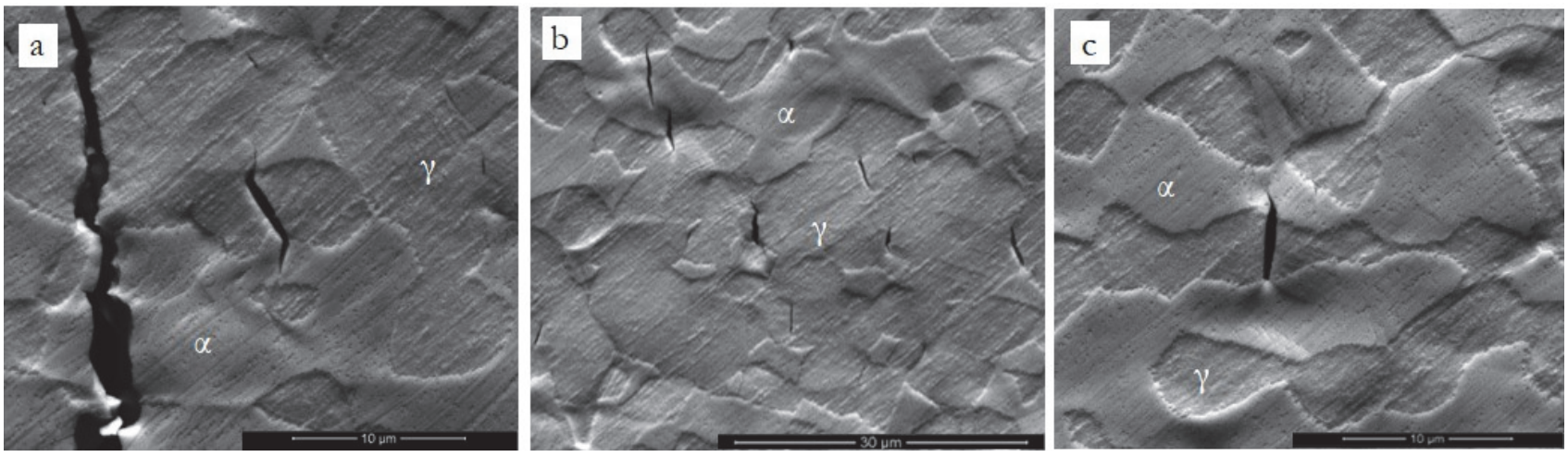

Figure 7: Secondary cracks on the ND surface of a HT 1110 tensile sample
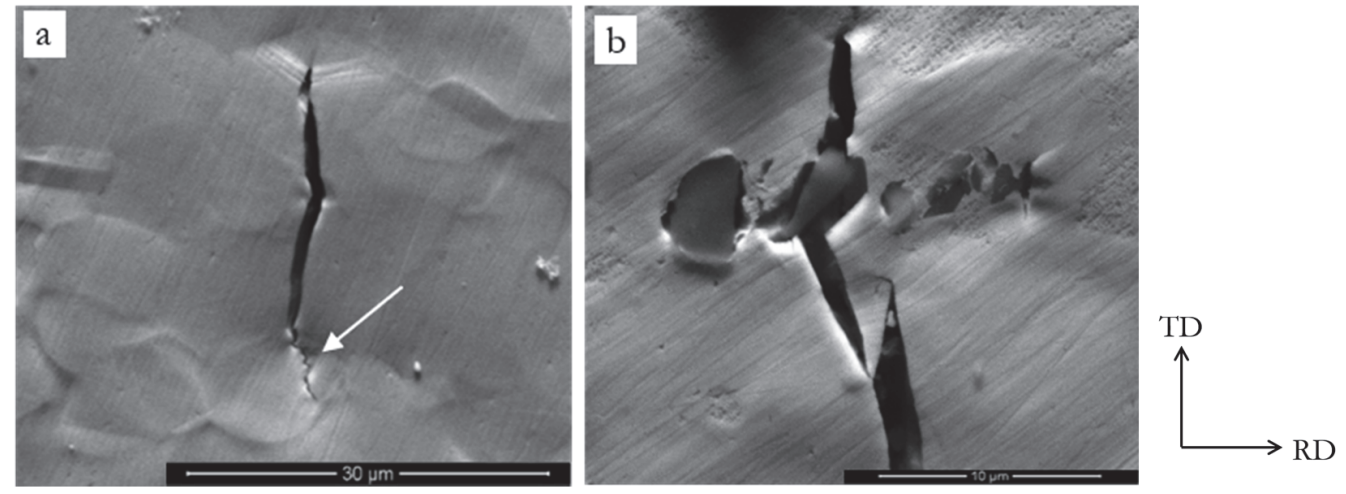

Figure 8: Secondary cracks on the ND surface of tensile samples: (a) zigzag crack (indicated by the white arrow) in an austenite grain in HT 1190 (b) Hydrogen cracks around alumina inclusions in HT 1110 


\section{CONCLUSION}

he influence of austenite phase fraction on the hydrogen sensitivity of duplex stainless steel was investigated in this work. Heat treatments were performed to create DSS with an austenite fraction of $50 \%$ and $44 \%$. Tensile tests in uncharged and hydrogen-charged condition were performed on these materials, based on which the following conclusions can be made:

Both heat treated samples suffered a considerable loss in ductility after hydrogen charging. For the sample with a $50 \% \gamma$ fraction, the elongation at fracture was reduced by $36.5 \%$. For the specimens with $44 \% \gamma$ this was $43.3 \%$.

- Loss of ductility, as quantified by the embrittlement index, was larger for the sample with a higher ferrite content. The sample had a higher hydrogen content and a higher hydrogen diffusion coefficient, contributing to its increased sensitivity.

- Fracture surfaces of specimens tested under the presence of hydrogen showed brittle fracture features on the edges. The depth of the zone with brittle features was related to the diffusion speed of hydrogen. The hydrogen distribution after one day of hydrogen pre-charging, simulated using the thin-plate solutions of Fick's second law, showed that hydrogen was not present throughout the thickness of the sample. The sample with $44 \% \gamma$, which had a higher overall diffusion coefficient for hydrogen, had a larger embrittled zone since hydrogen could diffuse over a greater distance in the given pre-charging time.

- Secondary cracking as hydrogen-assisted cracking was observed on the side surfaces of specimens tested with hydrogen and appeared to be primarily transgranular. Tensile specimens tested in air did not show this secondary cracking.

\section{ACKNOWLEDGEMENTS}

7 he authors acknowledge support from FWO (SB PhD fellow via grant 1S16618N) for L. Claeys, while T. Depover holds a senior postdoctoral fellowship of the Research Foundation - Flanders (FWO) via grant 12ZO420N. The authors also wish to thank the Special Research Fund (BOF), UGent (grant BOF15/BAS/062 and BOF01P03516) and the Research Foundation - Flanders (FWO) via grant 3G056519.

\section{REFERENCES}

[1] Azevedo, C.R. de F., Pereira, H.B., Wolynec, S., Padilha, A.F. (2019). An overview of the recurrent failures of duplex stainless steels, Eng. Fail. Anal., 97, pp. 161-188, DOI: 10.1016/j.engfailanal.2018.12.009.

[2] Johnsen, R. (2017).Hydrogen induced stress cracking of stainless steel in seawater - what do we know and what is still unknown? The Annual Congress of the European Federation of Corrosion, 20th International Corrosion Congress and Process Safety Congress 2017, Prague, Czech Republic.

[3] Popov, B.N., Lee, J.W., Djukic, M.B. (2018).Hydrogen permeation and hydrogen-induced cracking. Handbook of Environmental Degradation Of Materials Third Edition, Elsevier Inc., pp. 133-62.

[4] Francis, R., Byrne, G., Warburton, G.R. (1997). Effects of cathodic protection on duplex stainless steels in seawater, Corrosion, 53(3), pp. 234-240, DOI: 10.5006/1.3280465.

[5] Campbell, H.S., Francis, R. (1995). Simulated service test for hydrogen embrittlement of cathodically protected subsea bolting materials, Br. Corros. J., 30(2), pp. 154-160, DOI: 10.1179/000705995798114087.

[6] Depover, T., Laureys, A., Pérez Escobar, D., Van den Eeckhout, E., Wallaert, E., Verbeken, K. (2018). Understanding the Interaction between a Steel Microstructure and Hydrogen, Materials (Basel)., 11(5), pp. 698, DOI: $10.3390 / \mathrm{ma1} 1050698$.

[7] Robertson, I.M., Sofronis, P., Nagao, A., Martin, M.L., Wang, S., Gross, D.W., Nygren, K.E. (2015). Hydrogen Embrittlement Understood, Metall. Mater. Trans. A, 46(6), pp. 2323-2341, DOI: 10.1007/s11661-015-2836-1.

[8] Djukic, M.B., Bakic, G.M., Sijacki Zeravcic, V., Sedmak, A., Rajicic, B. (2019). The synergistic action and interplay of hydrogen embrittlement mechanisms in steels and iron: Localized plasticity and decohesion, Eng. Fract. Mech., 216, pp. 106528, DOI: 10.1016/j.engfracmech.2019.106528.

[9] Zapffe, C.A., Sims, C.E. (1941). Hydrogen embrittlement, internal stress and defects in steels, Trans. Am. Inst. Min. Metall. Eng., 145, pp. $1-37$.

[10] Troiano, A.R. (2016). The role of hydrogen and other interstitials in the mechanical behavior of metals (1959 Edward 
De Mille Campbell Memorial Lecture), Metallogr. Microstruct. Anal., 5(6), pp. 557-569, DOI: $10.1007 /$ s13632-016-0319-4.

[11] Oriani, R.A., Josephic, P.H. (1974). Equilibrium aspects of hydrogen-induced cracking of steels, Acta Metall., 22(9), pp. 1065-1074, DOI: 10.1016/0001-6160(74)90061-3.

[12] Birnbaum, H.K., Sofronis, P. (1994). Hydrogen-enhanced localized plasticity - a mechanism for hydrogen-related fracture, Mater. Sci. Eng. A, 176, pp. 191-202.

[13] Beachem, C.D. (1972). A New Model for Hydrogen-Assisted Cracking ( Hydrogen " Embrittlement "), Metall. Trans., 3(February), pp. 437-451.

[14] Depover, T., Verbeken, K. (2018). The detrimental effect of hydrogen at dislocations on the hydrogen embrittlement susceptibility of Fe-C-X alloys: An experimental proof of the HELP mechanism, Int. J. Hydrogen Energy, 43(5), pp. 3050-61, DOI: 10.1016/j.ijhydene.2017.12.109.

[15] Nagumo, M. (2004). Hydrogen related failure of steels - A new aspect, Mater. Sci. Technol., 20(8), pp. 940-950, DOI: $10.1179 / 026708304225019687$.

[16] Ortiz, M., Cuitiño, A.M. (1996). Ductile fracture by vacancy condensation in fcc. single crystals, Acta Mater., 44(2), pp. 427-436.

[17] Tsai, S.T., Yen, K.P., Shih, H.C. (1998). The embrittlement of duplex stainless steel in sulfide-containing $3.5 \mathrm{wt} \% \mathrm{NaCl}$ solution, Corros. Sci., 40(2-3), pp. 281-295, DOI: 10.1016/S0010-938X(97)00135-2.

[18] Chou, S.L., Tsai, W.T. (1999). Hydrogen embrittlement of duplex stainless steel in concentrated sodium chloride solution, Mater. Chem. Phys., 60(2), pp. 137-142, DOI: 10.1016/S0254-0584(99)00077-2.

[19]Zucchi, F., Grassi, V., Monticelli, C., Trabanelli, G. (2006). Hydrogen embrittlement of duplex stainless steel under cathodic protection in acidic artificial sea water in the presence of sulphide ions, Corros. Sci., 48(2), pp. 522-530, DOI: $10.1016 /$ j.corsci.2005.01.004.

[20] Luo, H., Dong, C.F., Liu, Z.Y., Maha, M.T.J., Li, X.G. (2013). Characterization of hydrogen charging of 2205 duplex stainless steel and its correlation with hydrogen-induced cracking, Mater. Corros., 64(1), pp. 26-33, DOI: $10.1002 /$ maco.201106146.

[21] Vaňová, P., Sojka, J. (2014). Hydrogen embrittlement of duplex steel tested using slow strain rate test, Metalurgija, 53(2), pp. 163-136.

[22] da Silva, B.R.S., Salvio, F., Santos, D.S. (2012).Hydrogen Embrittlement of Super Duplex Stainless steel Tube UNS S32750 Under Mechanical Stress., pp. 245-253.

[23] Olden, V., Thaulow, C., Johnsen, R. (2008). Modelling of hydrogen diffusion and hydrogen induced cracking in supermartensitic and duplex stainless steels, Mater. Des., 29(10), pp. 1934-1948, DOI: 10.1016/j.matdes.2008.04.026.

[24] Pohl, M., Storz, O. (2004). Sigma-phase in duplex-stainless steels, Zeitschrift Für Met., 95(7), pp. $631-638$.

[25] Depover, T., Escobar, D.M.P., Wallaert, E., Zermout, Z., Verbeken, K. (2014). Effect of hydrogen charging on the mechanical properties of advanced high strength steels, Int. J. Hydrogen Energy, 39(9), pp. 4647-4656, DOI: 10.1016/j.ijhydene.2013.12.190.

[26] Zakroczymski, T., Glowacka, A., Swiatnicki, W. (2005). Effect of hydrogen concentration on the embrittlement of a duplex stainless steel, Corros. Sci., 47(6), pp. 1403-1414, DOI: 10.1016/j.corsci.2004.07.036.

[27] Chou, S.L., Tsai, W.T. (1999). Effect of grain size on the hydrogen-assisted cracking in duplex stainless steels, Mater. Sci. Eng. A, 270(2), pp. 219-224, DOI: 10.1016/S0921-5093(99)00174-4.

[28] Luu, W.C., Liu, P.W., Wu, J.K. (2002). Hydrogen transport and degradation of a commercial duplex stainless steel, Corros. Sci., 44(8), pp. 1783-1791, DOI: 10.1016/S0010-938X(01)00143-3.

[29] Örnek, C., Reccagni, P., Kivisäkk, U., Bettini, E., Engelberg, D.L., Pan, J. (2018). Hydrogen embrittlement of super duplex stainless steel - Towards understanding the effects of microstructure and strain, Int. J. Hydrogen Energy, 43(27), pp. 12543-12555, DOI: 10.1016/j.ijhydene.2018.05.028.

[30] Depover, T., Wallaert, E., Verbeken, K. (2016). On the synergy of diffusible hydrogen content and hydrogen diffusivity in the mechanical degradation of laboratory cast Fe-C alloys, Mater. Sci. Eng. A, 664, pp. 195-205, DOI: $10.1016 /$ j.msea.2016.03.107.

[31] Claeys, L., Depover, T., De Graeve, I., Verbeken, K. (2019). First observation by EBSD of martensitic transformations due to hydrogen presence during straining of duplex stainless steel, Mater. Charact., 156, pp. 109843, DOI: $10.1016 /$ j.matchar.2019.109843.

[32] Abraham, D.P., Altstetter, C.J. (1995). The effect of hydrogen on the yield and flow stress of an austenitic stainless steel, Metall. Mater. Trans. A, 26(11), pp. 2849-2858, DOI: 10.1007/BF02669643.

[33] Takakuwa, O., Mano, Y., Soyama, H. (2014). Increase in the local yield stress near surface of austenitic stainless steel due to invasion by hydrogen, Int. J. Hydrogen Energy, 39(11), pp. 6095-6103, DOI: 10.1016/j.ijhydene.2014.01.190. 
[34] Kheradmand, N., Johnsen, R., Olsen, J.S., Barnoush, A. (2016). Effect of hydrogen on the hardness of different phases in super duplex stainless steel, Int. J. Hydrogen Energy, 41(1), pp. 704-712, DOI: 10.1016/j.ijhydene.2015.10.106.

[35] Barnoush, A., Zamanzade, M., Vehoff, H. (2010). Direct observation of hydrogen-enhanced plasticity in super duplex stainless steel by means of in situ electrochemical methods, Scr. Mater., 62(5), pp. 242-245, DOI: $10.1016 /$ j.scriptamat.2009.11.007.

[36] Martin, M.L., Fenske, J.A., Liu, G.S., Sofronis, P., Robertson, I.M. (2011). On the formation and nature of quasicleavage fracture surfaces in hydrogen embrittled steels, Acta Mater., 59(4), pp. 1601-6, DOI: 10.1016/j.actamat.2010.11.024.

[37] Kerlins, V. (1998).Modes of fracture. ASM handbook Volume 12: Fractography, ASM International, p. 857.

[38] Lynch, S.P. (1984). A fractographic study of gaseous hydrogen embrittlement and liquid-metal embrittlement in a tempered-martensitic steel, Acta Metall., 32(1), pp. 79-90, DOI: 10.1016/0001-6160(84)90204-9.

[39] Turnbull, A., Hutchings, R.B. (1994). Analysis of hydrogen atom transport in a two-phase alloy, Mater. Sci. Eng. A, 177(1-2), pp. 161-171, DOI: 10.1016/0921-5093(94)90488-X.

[40] Claeys, L., Depover, T., De Graeve, I., Verbeken, K. (2019). Electrochemical Hydrogen Charging of Duplex Stainless Steel, Corrosion, 75(8), pp. 880-887, DOI: 10.5006/2959.

[41] Zheng, W., Hardie, D. (1991). Effect of structural orientation on the susceptibility of commercial duplex stainless steels to hydrogen embrittlement, Corrosion, 47(10), pp. 792-799, DOI: 10.5006/1.3585190.

[42] Oltra, R., Bouillot, C., Magnin, T. (1996). Localized hydrogen cracking in the austenitic phase of a duplex stainless steel, Scr. Mater., 35(9), pp. 1101-1105, DOI: 10.1016/1359-6462(96)00293-X.

[43] Magnin, T., Chambreuil, A., Bayle, B. (1996). The corrosion-enhanced plasticity model for stress corrosion cracking in ductile fcc alloys, Acta Mater., 44(4), pp. 1457-1470, DOI: 10.1016/1359-6454(95)00301-0.

[44] Claeys, L., Depover, T., De Graeve, I., Verbeken, K. (2019). Hydrogen-assisted cracking in 2205 duplex stainless steel: initiation, propagation and interaction with deformation-induced martensite, Mater. Sci. Eng. A, under review.

[45] Koyama, M., Akiyama, E., Sawaguchi, T., Raabe, D., Tsuzaki, K. (2012). Hydrogen-induced cracking at grain and twin boundaries in an Fe-Mn-C austenitic steel, Scr. Mater., 66(7), pp. 459-462, DOI: 10.1016/j.scriptamat.2011.12.015.

[46] Laureys, A., Van den Eeckhout, E., Petrov, R., Verbeken, K. (2017). Effect of deformation and charging conditions on crack and blister formation during electrochemical hydrogen charging, Acta Mater., 127, pp. 192-202, DOI: 10.1016/j.actamat.2017.01.013.

[47] Tiegel, M.C., Martin, M.L., Lehmberg, A.K., Deutges, M., Borchers, C., Kirchheim, R. (2016). Crack and blister initiation and growth in purified iron due to hydrogen loading, Acta Mater., 115, pp. 24-34, DOI: 10.1016/j.actamat.2016.05.034. 